\title{
Central Park and its Provision
}

\section{ADAM O'BRIEN (D)}

ब나

Open Library of Humanities

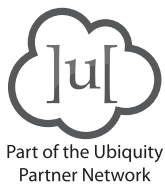

Part of the Ubiquity

\begin{abstract}
In Intelligence Work: The Politics of American Documentary, Jonathan Kahana paraphrases Hannah Arendt as follows: 'Public things do not just appear, in some quasi-natural event, but are the result and legacy of human fabrication, of work'. Through a detailed interpretation of Frederick Wiseman's Central Park (1990), this essay asks what it means for a film to register and document this fabrication, and how the fact of provision can be made present and meaningful in such a film. It brings together three distinct but related critical ideas - the commons, infrastructure and the everyday - to examine the formal and aesthetics means by which Central Park depicts urban phenomena not as an immanent condition, but rather as something which has deliberately and actively been made available to a public.
\end{abstract}

CORRESPONDING AUTHOR:

\section{Adam O'Brien}

Department of Film, Theatre $\&$ Television, University of Reading, UK

adam.obrien@reading.ac.uk

\section{KEYWORDS:}

documentary; Wiseman; New York; commons; infrastructure; everyday

TO CITE THIS ARTICLE:

O’Brien, A. 2021. Central Park and its Provision. Open Screens, 4(1): 9, pp. 1-13. DOI: https:// doi.org/10.16995/os.47 


\section{INTRODUCTION}

This essay considers Central Park (Frederick Wiseman, 1990) as a film which asks what counts as a public, and more specifically what counts as a public provision. Michael Warner has argued that a public may be considered in a general sense (as the public), or according to two other alternative frameworks; as a 'concrete audience, witnessing itself in visible space', or through the circulation of texts which address and pre-empt a 'readership' (2002: 50). In Central Park, I observe something of a combination of these two alternatives, whereby a public does indeed gather and witness one another, but also whereby that public is defined by a common access - albeit to a resource, rather than a text. ${ }^{1}$ The film's formal and rhetorical engagement with its subject (the eponymous park in Manhattan) constitutes a particularly vivid example of what it means to imaginatively depict a resource as a socially available facility. As well as offer an interpretation of the film, I aim to develop a more alert and imaginative sense of infrastructure in cinema as (actual or potentially) shared facilities which make possible certain activities and experiences, and to argue that their availability is not an inert condition.

While I hope that this approach to Central Park may also illuminate some new ways of understanding other works in Wiseman's vast oeuvre, I am certainly not proposing anything like an alternative 'meta-reading'. For very good reason, critics and scholars have often emphasised how Wiseman's films rigorously hold institutions to account, and how they 'investigate the social mechanisms that constrain and ultimately constitute the subject as an object to be manipulated and controlled' (Armstrong, 1989). The question of provision is not introduced here in an effort to disprove the (almost irrefutable) claim that Wiseman's films critically expose deeply problematic patterns and structures in public and quasi-public settings, but rather that the very existence and potential of those settings have a significance and meaning stretching beyond the experiences of filmed individuals in given moments (an interpretive move which begins to reframe the ethical questions we ask of Wiseman's engagement with his subjects - human and otherwise). Similarly, this essay does not interrogate Wiseman's work in relation to important debates surrounding performativity and technical practice as they relate to American documentary, or to Direct Cinema in particular. ${ }^{2}$ While those contexts are absolutely necessary to a full appreciation of Wiseman's significance as a documentarian, I hope to show that other points of emphasis and reference (drawing on scholarship outside of documentary studies) can bring to the fore overlooked characteristics of his subject matter, clustering around the idea of provision - an idea I will approach by way of three separate but interlocking concepts; the commons, infrastructure and the everyday.
Less than three minutes into Central Park, there is a shot which is characteristic of its interest in provision and can usefully introduce some of the themes of this essay. The film has begun with a short sequence of a nighttime concert in the park, followed by early-morning signifiers (birdsong, a person sleeping rough on a bench, office workers walking in orderly fashion and uniform direction); it then cuts to a very long shot of a figure sunbathing on well kempt lawn. The composition is precise and deliberate; the man is positioned centrally on the x-axis, but low in the frame, leaving an expanse of grass 'above' and behind him, the space neatly condensed by the telephoto lens. ${ }^{3}$ But almost as soon as this visual balance is established, it is interrupted by a lawn tractor which drives into the frame from the left. The tractor is moving forward in a straight line (diagonally toward the bottom right of the frame), and though it looks certain to bypass the sunbather, the driver nevertheless gently honks a horn, prompting the sunbather to lift and wave a hand in response. In a rather simple sense, the bathing/mowing conjunction illustrates in microcosm one of the film's core ideas; that the park's capacity for leisure is contingent on machinery and labour and organization. But it is made slightly more complex by the short interaction - the horn and the wave - from which we are too far as viewers to discern or interpret facial expressions (Figure 1).

What is the spirit of this fleeting engagement, and on what terms do these people meet? Is the horn a gesture of greeting, warning or admonishment? Is the wave one of greeting, gratitude or dismissal? The vital ambiguity emerges not just because we are insufficiently close to the people, but because we cannot confidently answer the question of who is serving whom. Most obviously the driver is serving the sunbather - one is at rest, the other is working to maintain the conditions of that rest - but, this being a municipal park, we know that the sunbather is in receipt of a resource which is not for them and them alone, and which they have neither earned nor attained in any direct sense. The economic and political coordinates by which we might normally interpret conflict

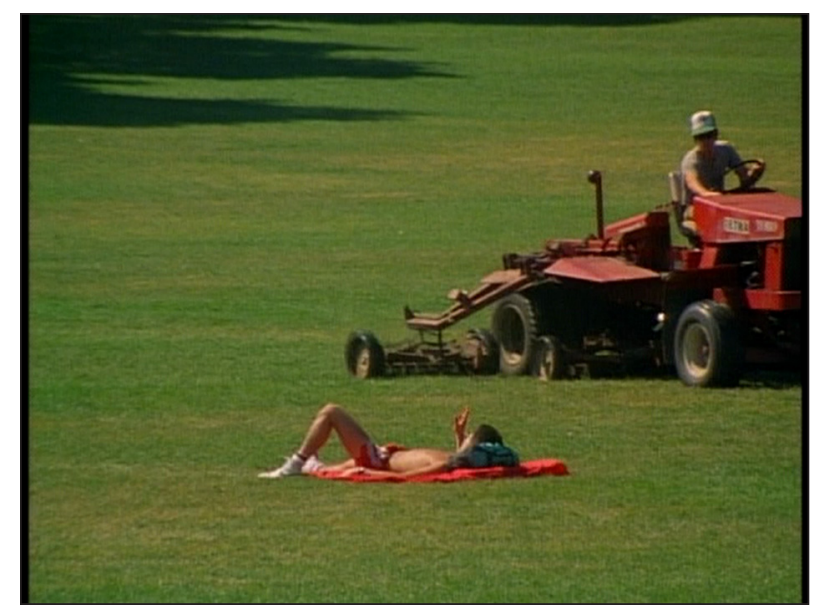

Figure $1 \mathrm{~A}$ small greeting. 
or disruption in situations of service and employment (examples abound in narrative cinema relating to paid domestic labour, diners and restaurants, shops, offices, etc.) do not quite apply here; both the activity and its location are marked by a kind of publicness. By this I mean not only something that is visible and non-private, but something that is characterized more thoroughly by it being shared and available, and by all the challenges and affordances bound up in that condition. This essay considers how Central Park registers that condition.

\section{PUBLIC WORKS}

As the starting point for his book about urban planning and ethics, Building and Dwelling, Richard Sennett argues for a return to, or resurrection of, a pair of French terms: ville and cité. Ville refers to the 'facts' of a city, its buildings and borders and laws; cité, meanwhile, denotes 'the character of life in a neighbourhood, the feelings people harbour[ed] about neighbours and strangers and attachments to place' (2018: 1). Sennett broadly sees the ville as the domain of engineers and bureaucrats, and the cité as the site of experience (residents, pedestrians, commuters, etc.), and as the 'stuff' attended to by artistic chroniclers of the city. The animating question of his book is how the 'brute fact' of a city's given form 'can be reconciled to the swift changes of modern life, to its liquid, dissolving flow of old economic, social or religious forms'. How, in other words, 'can one relate a solid ville to a liquid cite?' (30).

Cinema studies has not overlooked this dual nature of city life. Examples abound of scholarship which draws enlightening and convincing lines of connection across moving images and urban phenomena-throughquestions of, for example, planning, architecture, race, production, distribution, phenomenological experience, gender, formal expressivity, mapping, framing and storytelling. ${ }^{4}$ I propose that there is nevertheless an aspect to Sennett's conception which remains relatively unfamiliar to the discipline, and in particular to interpretive criticism. This is the aspect of provision. Senett's question about relating ville to cité is not offered as one for speculative reflection, but as an articulation of something urban planners must somehow resolve, a conundrum that demands of them a solution made tangible - for example as a traffic intersection, as a sewage system, as a sports stadium, or as a rail-network extension. In Sennett's terms, these are how the ville and the cité relate. Far from immanent the ville is the result of will, of compromise, of a human decision to extend something to a political community. Cities are provisional not just in the sense that they are in constant flux, then, but in the sense that they provide.

To consider this need not mean overlooking the deep and sharp injustices in cities. Their provision can be (and almost always is) partial and uneven and complicit to some extent with coercive and exploitative forces. For example, the young black men who gather at night in Central Park in the opening episode of When They See Us (2019) and the older white couple who visit Central Park in Annie Hall (1977) cannot be said to have been provided for in a genuinely common or consistent way. ${ }^{5}$ There is some risk of naiveite in positing Central Park as a kind of idyllic space of egalitarian civility, outside of socio-historical forces. This would be both mistaken and ironic, given the interest Central Park takes in the role of the Central Park Conservancy (whose establishment in 1980 was a deeply politicized response to the perceived unruliness of the park). But it is nevertheless valid to ask not only how urban forms control or confront their publics, but also what they allow for, and what they allow for on a shared scale or register. For while it is true that the variety of subjective experiences to which a city can play host is unimaginably broad, the commonness of urban provision is surely part of that experience. I suggest that, in cinema, the ville is too often understood as a given condition to which the cité responds, channeled by filmmakers and/or film subjects as (for example) alienation, threat or stimulation.

Even in celebratory and rhapsodic treatments of the city, 'the urban' is so often something to be confronted with, rather than received. Charlotte Brunsdon, in her critical survey of 'tropes of city discourse' in film and television studies, notes the rather contradictory way in which 'the rhythms of the city' are often presented as that 'which can be analyzed, but to which there must also be surrender' (2012: 222-223), a surrender which is invariably tied up with discourses and definitions of modernity and modern experience. Central Park is by no means outside of modernity, or unrelated to the more familiar themes of urban-film scholarship, but it departs in important ways from the tropes Brunsdon identifies as limiting and self-perpetuating: 'alone in the crowd; unexpected juxtaposition; disregarded detail; fleeting glimpse of beauty; scarred building; material traces of past history; vanished landmarks' (223). While each of these could be said to appear in some shape or form during Central Park, the film's most significant attempts to depict and represent its immediate world lead us elsewhere - away from subjective experience, and towards the fact of something being public.

In Intelligence Work, a book to which the current essay owes a considerable debt, Jonathan Kahana paraphrases Hannan Arendt as follows: 'Public things do not just appear, in some quasi-natural event, but are the result and legacy of human fabrication, of work' (2008: 20). Kahana notes that critical debates about the public (particularly the work of Habermas and Arendt) did not get taken up by documentary-film studies as much as one would expect, given the widely held understanding of documentary as a mode which tends towards a public address. 'To live together in the world', writes Arendt, 'means essentially 
that a world of things is between those who have it in common' ([1958] 1998: 52). Addressing shared resources and public-facing institutions, Wiseman's documentaries - the most well-known of which include High School (1968), Hospital (1970), Public Housing (1997) and Ex Libris (2017) - could be said to take this commonness as their subject, resisting as they do what Arendt describes as 'modern enchantment with "small things"'(52). Wiseman's films are not distinctive for being concerned with the ideal of social cooperation (a familiar conviction in many non-fiction films), but rather for documenting the complex social labour, cooperative or otherwise, which is expended in the provision of goods, services and resources. Not just work, but of work for a public.

If this can be said to constitute a philosophical or ethical principle which recurs throughout Wiseman's films (and a fuller project would be required to substantiate that claim, and to track the irony and critique which colors its expression), then it finds an especially appropriate subject in Central Park. New York City's most famous public space is a vivid figuration of public-mindedness, even if its history is certainly not one of uncomplicated benevolence. A stronghold of nonexclusivity in a city where private accumulation has been violently instrumental in so many ways, Central Park both serves and defies Manhattan. As Sennett recounts, Frederick Law Olmsted envisioned the park as something which would provide a space for social congregation on an inclusive scale: 'inclusion was more possible', he writes of Olmsted's ideals, 'in an impersonal space of strangers than in the more intimate space of neighbours' (2018: 45). That vast engineering efforts were required to fabricate a place intended to function as a 'natural' resource is not for Sennett an ignoble secret or even an irony, but rather evidence of a decisive act of provision on the part of Olmsted and the city - or what he calls the 'provoking proposition' that 'social inclusion can be physically designed' (47). ${ }^{6}$ Design and maintenance are visible and prominent throughout Central Park, both in the form of manual labour and bureaucratic discourse, but it does not follow that the film is somehow critically unmasking an 'illusion of natural space' and revealing a 'hyperreal space', as Barry Keith Grant argues (1992: 220). Considered in accordance with Sennett's words on Olmsted, Central Park could instead be seen as a film which understands the park's status as a long-standing public resource.

The film does not directly engage with this history or present a reasoned argument for the civic validity of Central Park. But it does find many ways to encourage an understanding and view of the park (and, by extension, the city?) as something irreducible to backdrop or location by dint of its varied utility - as something that is constantly made to be constantly used. Before venturing into details of how these meanings are achieved by the film, I will consider in greater detail what is implied and signaled by the term 'provision', and in particular how it intersects with questions of access and availability (the commons), of circulation and distribution (infrastructure), and of regularity and reliance (everydayness).

\section{ELEMENTS OF PROVISION}

Ori Levin describes how city symphony films of the 1920 s asserted commonness through their emphasis on 'clock time' (2018); Wiseman's film could be said (at the risk of simplification) to instead foreground shared space, rather than shared time. Central Park seems to offer a vivid example of those functions widely associated with the commons; it is a designated area, protected from individual ownership or purchase, providing something deemed to be of broad and deep value or necessity. To consider Central Park, and a film about that park, in relation to the commons is not to overlook or ignore its knotted social and political history, founded in part on the displacement of many non-rich and non-white citizens. ${ }^{7}$ (Indeed, the park is not common property but public, government, property.) And yet its social promise is not entirely illusory, and answers to Massimo De Angelis's definition of the commons as a 'non-commodified means of fulfilling people's needs' (An Architektur 2010). In their history of Central Park, Rosenzweig and Blackmar go so far as to claim that its creation 'as public property initiated a remarkable redefinition and expansion of city government's responsibilities to its citizens' (1992: 6). De Angelis, though, does not emphasize the fixed or legal status of the commons; they are, he says, "necessarily created and sustained by communities' and are made possible by the ongoing act of commoning, 'the social process that creates and reproduces the commons' (An Architektur 2010). Provision not as a gift or an arrangement, but a continuing social dynamic.

In her introduction to the inaugural issue of ASAP/ Journal on artistic practice and the commons, Amy J. Elias notes something of a 'fall' from the original (pre-modern) meaning of the term - 'spatial territories owned by a legal entity and used for communal profit by specifically defined groups' - towards a more confused idea warped by industrial capitalism and market imperatives (2016: 4). Elias distinguishes the spatial basis of a commons from the discursive basis of a public - 'unlike commons, which grow from communities engaging in formal or informal contractual relations, publics are communities of address' - while also bringing a skeptical critique to sites and gatherings of apparent, but illusory, togetherness, of which municipal parks are certainly an important example (6). 'Controlled urban spaces', write Elias, 'attempt to project an image of cohesion, peace and unity - and thus an image of a certain kind of public - through their built environments of enclaves and ceremonial structures' (10). In The Undercommons: Fugitive Planning and Black 
Study, Stefano Harney and Fred Morten charge that the very idea of social governance is ethically compromised: 'If public administration is the competence to confront the socialisation thrown up continuously by capitalism and to take as much of that socialisation as possible and reduce it either to something called the public or something called the private', then it is not possible to describe such 'reproduction of dispossession as having an ethical dimension' (2013: 36-37). For Harney and Morten, even to accept that different categories of our social world (the state, the economy, etc.) stand in 'discrete, spatial arrangement each to the other' is to risk perpetuating their injustices (36). From their perspective, any commons that acknowledges the logic of 'professionalization' is already subsumed and undermined by it.

Lauren Berlant, like Elias, identifies the commons as a necessary concept for the contemporary arts and humanities, but cautions against its implicit idealism, its 'way of positivizing the ambivalence that saturates social life about the irregular conditions of fairness' (2016: 395). Rather than a cue to lament the social ravages of post-industrial capitalism, the 'better power of the commons' for Berlant 'is to point to a way to view what's broken in sociality, the difficulty of convening a world conjointly, although it is inconvenient and hard, and to offer incitements to imagining a livable provisional life' (395). In reference to Ralph Waldo Emerson's writing on Boston Common, Berlant suggests that this 'a place he goes not to possess but to be possessed, to submit to being dispossessed of property' (400). The commons provide not only a particular resource space, energy, and sustenance, but also the opportunity for its users to suspend their reliance on ownership and property. This is part of what Berlant designates 'the affective work of becoming common'; the fact of provision itself becomes something to be felt, to be addressed, and to be understood (401).

Berlant frames her reflections on the commons with a discussion of a related but distinct term, infrastructure. As 'the living mediation of what organizes life', infrastructure establishes the terms within which a commons can function, and is the aggregate of those 'systems that link ongoing proximity to being in a world-sustaining relation' (2016: 393). Berlant draws on a number of insights and perspectives developed in infrastructure studies, in influential work by writers such as Paul Edwards, Deborah Cowen, Geoffrey Bowker and Susan Leigh Star. Amongst the most familiar of these is the observation that infrastructure becomes visible (and critically active) when it breaks down, allowing us to 'see the machinery of the separation that has induced relations among things' (402). Imre Szeman notes that this understanding of infrastructure as culturally-embedded-to-the-point-ofinvisibility (or breakdown) prompts 'a double movement in thinking about aesthetics and resources' which he paraphrases as follows: 'We first say: why haven't resources been figured more prominently given how important they are for capitalist modernity? And second: we begin the work of tracking down the aesthetic or epistemic registers where representations of resource culture do arise' (Bellamy et al., 2016). My reading of Central Park is, in part, an argument that breakdown need not be the sole or primary 'epistemic register' by which we come to know infrastructure, and that the notion of provision helps us become more alive and alert to its everyday functioning. In an enlightening essay on infrastructure and temporality, Akhil Gupta argues for a 'dynamic view' of infrastructure which addresses the 'constant struggle between renewal and ruination', as an alternative to the 'static view' which waits for break down or disaster for it to be 'thrust into the temporality of birth, life and decay' (2018: 73). Gupta's call for a perspective which is both dynamic and undramatic, for a view which understands infrastructure's unremarkable provision as well as its power to shape 'the biopolitical through its role in imaginations of the future', is something of challenge for film-and-media scholarship, to say the least (64).

It is a challenge closely related to what is perhaps the central conundrum in the field of everyday aesthetics, wherein the act of bestowing attention on a phenomenon of everyday life threatens to automatically undermine its everydayness. As Yuriko Saito articulates it, 'are the ordinary and the everyday as ordinary and everyday always incompatible with the aesthetic? Do they always have to be put 'out of gear' or 'distanced' from the normal flow of experience in order for its aesthetic potential to be actualized[...]?' (2017: 22). Indeed Jane Forsey argues that the study of everyday aesthetics can roughly be divided according to different writers' response to that apparent contradiction; between those who extend aesthetic consideration to 'exceptional' objects or experiences from ordinary life, and those who argue that the full spectrum of quotidian life can be understood aesthetically, and in relation to aesthetic qualities and judgements (2014). Although the current essay is one focused on a work of representational art, which removes it quite definitely from the emphasis placed by everyday aestheticians on those things not bracketed for contemplation and interpretation, I suggest that some animating questions considered by thinkers in this field can help to inform the quality of provision at play in Central Park.

As an aesthetic object that documents, represents and expresses a site of everyday activities, Central Park partakes not just in the everyday-aesthetics debate about exceptionalism summarized by Forsey, but also joins the longer lineage of works which offer a sustained reflection on the undramatic and the quotidian - including the writings of Henri Lefebvre, Michel De Certau, Stanley Cavell, Kathleen Stewart and Lauren Berlant. Lefebvre is perhaps the most forceful of these in arguing for the 
necessity (and difficulty) of apprehending what he calls the 'unmysterious depths' of everyday life (2014: 157). Writing as part of a Marxist project against the tendency towards 'contempt for productive labour' he finds in most literary or philosophical work purporting to address 'the real' (51), Lefebvre understands the everyday as the murky background from which known relations and superior activities (scientific, political, aesthetic) are picked out' - something like the 'leftovers' which remain overlooked and misunderstood when intellectuals and artists have gleaned what they deem significant and worthy of attention (272). Given his Marxist worldview, it is not surprising that Lefebvre's diagnosis of everyday malaise under capitalism has strong affinities with the language of the commons; his declaration that what matters is not possession of a 'a thing or a living being or a human being or a social reality' but rather the ability to 'enjoy it in the human, total meaning of the word' even returns us to Berlant and to Emerson, for whom the freedom from ownership was an important quality of the commons, and what it can provide (176).

Provision is a difficult quality or process to ascertain in a creative work, even when (as is the case in many Wiseman films) it is the direct subject of conversation and debate. How can we locate or understand it as an element of everyday experiences, and of representations of what Paul Henley describes, in his recent history of ethnographic film, as 'the customary and reiterative' $(2020,15)$ ? Jane Forsey proposes that the concept of 'design' can help direct a middle path in everyday aesthetics, by speaking to both exceptional objects and basic requirements - and her terms help to articulate how provision too can be understood: 'I suggest that we replace the notion of meaning with that of function in our methodology of the everyday: an ordinary object does not need interpretation, and was not created to communicate something to us. But it was designed to be used, and only by using it and assessing its success in fulfilling its function can we make an aesthetic judgement of its merits' (2015: 18). Given that I am addressing an aesthetic object (a film), I do not follow Forsey in doing away with meaning; but the suggestion that we focus on what it means for something to fulfill its function is a very productive one when considering a work such as Central Park - in which the fulfilment of function is itself meaningful.

\section{THE COMMON PARK}

As is often the case with Wiseman's films, the distinctive rhetoric of Central Park is achieved to a considerable extent by how the film is structured and where it apportions its attention. ${ }^{8}$ This is by no means always a case of attention as endorsement (see, for example, the 'over' emphasis on American citizens in Canal Zone
(1977) and that film's pointed disinterest in the canal and in Panamanian subjects), but it is a key facet of the films' point of view, not least because of the limited stylistic inflection at the level of individual shots and scenes. In Central Park, this attention is distributed mainly across four types of park activity: unstructured public use (such as jogging and sun bathing); structured public use (such as concerts and rallies); maintenance (such as tree surgery and bricklaying) and bureaucratic oversight (the meetings and activities of the Central Park Conservancy) as located 'behind closed doors' in non-public meetings. ${ }^{9}$ In summary, Central Park acknowledges through its form that the park's social life, its provision, is anything but organic or spontaneous.

Considered in terms of the commons, Central Park's siloing of people and activities seems to deny the promise of 'a self-defined community', of 'commoners who are actively engaged in negotiating rules of access and use' (Baldauf et al., 2016: 21), to quote the editors of Spaces of Commoning, who also go on to describe how 'the commons in the making depend on a continuous subjection to scrutiny', examining the 'norms and conventions of hierarchization and exclusion' - and it is this latter sense of commoning as a process that Central Park articulates (24). One of the most widely stated claims in literature on the commons is that it cannot be understood as an arrangement or structure, but rather a confederation of principles which guide ongoing action. That Central Park never settles on anything like a utopian synthesis of its constituent parts is an important reflection, and realization, of this restlessness.

An example of the film's refusal to illustrate (and risk petrifying) the park's ideal of commonality can be found in a quietly compelling scene in the Conservancy's meeting room. Documenting people talk, at length, and often without apparent resolution, is one of the main ways in which Wiseman shows the commons at work in his films more broadly. Also characteristic of his method is the absence of on-screen text revealing or confirming details about the roles and responsibilities of those in positions of authority - a technique which draws our attention away from someone's position within a bureaucratic system and leaves more 'room' for the prospect that they are engaging on other terms, terms not immediately reducible to titles or labels. The Conservancy staff are discussing strategies for deterring mountain-bike use in the park. For much of the meeting, the language used by the chairperson to describe the situation could be described as anti-social; 'staking out', 'targeting enforcement', 'making an example', 'broad prohibition', 'taking bikes as evidence', 'waging a war'. But almost imperceptibly, the conversation morphs into one about the bikers' apparent betrayal (though this word is not used) of the park's mission of fair and common access. 'There is a principle here', Elizabeth Barlow Rogers (President of the Conservancy) argues, 'which is a principle 
of sequestering pieces of the park and designating them for special interest groups; and when you do that you lose the most precious thing the park has, which is its free open space for everybody.' What had appeared to be exclusionary and combative discourse now takes on a very different hue; the group have been challenged by the bikers to reflect on the park's provision, and although the ostensible result is just a restatement of the official restrictions ('the process of informing people of the rules and what's expected on them is a timeless one', the Parks Commissioner muses rather wistfully), the film's documenting of this is itself significant. One imagines that many documentary filmmakers would be tempted to illustrate the verbal exchange with images of the 'free and open space' being described, but that would signal a result or synthesis of the kind that Central Park is not willing to delineate.

The distinction between discourse and activity, management and use, does not hold for the entire film. In one sequence, members of a pacifist gathering are instructed to stop selling paraphernalia, much to their frustration and dismay. One particularly vocal member of the group even compares the application of park rules to the arbitrary and unbending laws of Nazi Germany, and another member breaks into tears, aghast at what she sees as a suppression of free speech. 'I never thought this would happen where I live, in this country', she cries. 'This is Russia, this isn't America' (Figure 2). What are we to make of this sudden expansion of the film's scale? Is this a case of what Jonathan Kahana describes, in his writing on 'social documentary', as an 'allegorical displacement of particular details onto the plane of general significance' (2008: 26)? A different way of posing this question would be to ask what the rally members themselves had perceived the relationship between the park and the world (or their nation state) to be. There is in their demeanor and their words the sense of having been let down by the promise of a space or situation in which rules would need not apply, or in which 'common sense'

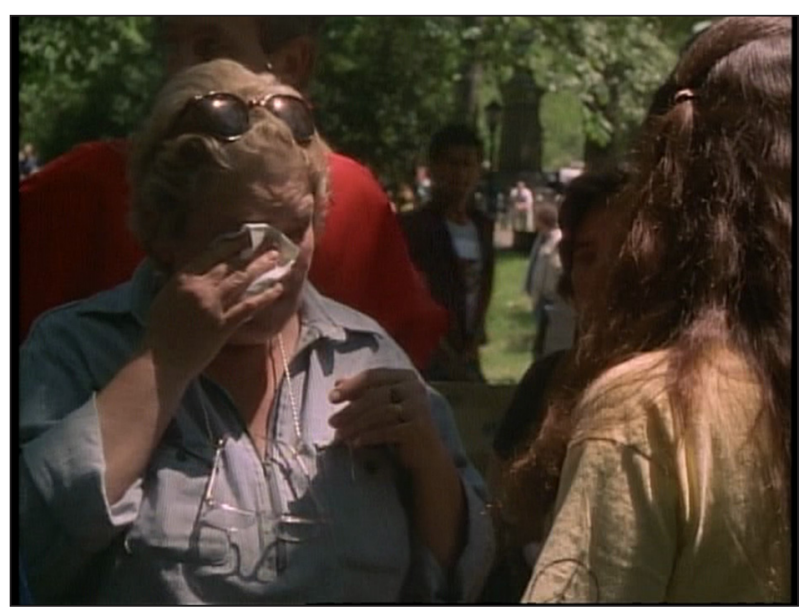

Figure 2 'I never thought this would happen where I live, in this country'. would hold sway. Is their consternation a response to the park being both continuous with and discontinuous with political reality? That we can observe the park as a space which sustains this kind of dichotomous social existence is a sign, I suggest, that Central Park does not adopt the register or mode of address described by Kahana. The park is not a metonym. Rhetorical displacement is attempted by some of the film's subjects, but Central Park shows that activity to itself be something enabled by Central Park, where citizens can hope to access, to borrow Erica Stein's eloquent phrase, 'an everyday not unduly subject to the rapid turnovers and dispossession endemic to the neoliberal city' (2019: 367). One important sequence in the film shows members of the 'Perimeter Association' visit the wealthy occupants of buildings directly adjacent to the park, and explain to them the details and governance of the park's border. In a basic sense, this is a document of the Association's attempt to fundraise, but it can also be understood as a reminder on the part of the film that the park is a finite place, abutted on all sides by a city which does not necessarily provide the same capacity for commonality.

\section{THE INFRASTRUCTURAL PARK}

Lighting is one of the key features of urban life that cinema is often said to have documented, reflected and embodied as part of its 'pact' with modernity. Writing specifically about Yasujiro Ozu's Sono yo no tsuma/That Night's Wife (1930) in relation to German 'street films', Daisuke Miyao suggests that it 'not only displays, with a critical view, a historical world that increasingly is defined by the role of electrical light but also contributes to the depth of a modern world of spectacle' $(2014,196)$, and a number of scholars have convincingly demonstrated how urban and architectural deployments of light influenced cinematic form and meaning - especially in the early decades of the twentieth century. ${ }^{10}$ Artificial light can also be considered as a quintessentially infrastructural subject, a particularly clear demonstration of what it means for a complex technological undertaking to have become 'second nature' to a social world. The urban blackout is perhaps rivalled only by the braking dam in its capacity for signaling infrastructural dependence through infrastructural failure. ${ }^{11}$ Aerial, cityscape shots of sudden power failures (often 'answered' by an equivalent short of sudden restoration) are a familiar convention of spectacular narrative cinema, but also, I suggest, further evidence of our overreliance on failure as evidence of provision.

Amongst the very first things we see in the opening seconds of Central Park is a band performing on stage at night, captured in long-shot and in profile, from a notespecially advantageous angle. Rather than cut in for a more detailed view of the performers (a technique 
Wiseman invariably denies himself), or across to the audience we assume is present, the film cuts up to a bank of stage lights, and then in again to a slightly closer view of the lights. This shot is not especially striking in its visual quality, and nothing about the lighting technology we see - other than its being there - seems to warrant particular attention. Rather, the shot subsequently becomes the first part of a short, poetic triad of images; from the stage lights we cut to a solitary streetlamp (one of approximately 1600 in the park), and from that to a frame-filling image of the moon. The transitions tell us little or nothing about spatial or temporal relations, and the short sequence instead proposes allegorical (or at least non-locatable) relations between the three subjects. The move from stage lighting to practical lighting to moonlight seems to want to 'say something', through montage, about technology, nature, energy and the park's taken-for-granted conditions. But it is telling that this montagist mode is not continued or returned to, and is instead replaced by a style which almost seems to deny its own potential for inflection.

A woman, Elizabeth Barlow Rogers, is on the phone (Figure 3 ). She sits at a large, solid desk adorned with many papers and a huge rolodex. A series of framed archival photos hang on the wall behind Rogers, who is comfortable and assured, if a little squeezed into her spot between the desk and wall. An establishing shot moments before had informed us that this is the Parks Department's administrative headquarters, but no other contextual information is offered to help us decipher the conversation we 'join' after it is well underway. (We see here another recurrent convention of Wiseman's filmmaking, the one-sided phone conversation.) Rogers is evidently deploying a degree of authority and seniority with whomever is on the line, to progress a matter about which she is unsatisfied. The matter, it soon transpires, is lighting design for the park; it seems Rogers is urging a contractor to apply more care and consideration on a model, and to revisit specifications for both the physical lamp (its ornamental features and its proportions) and

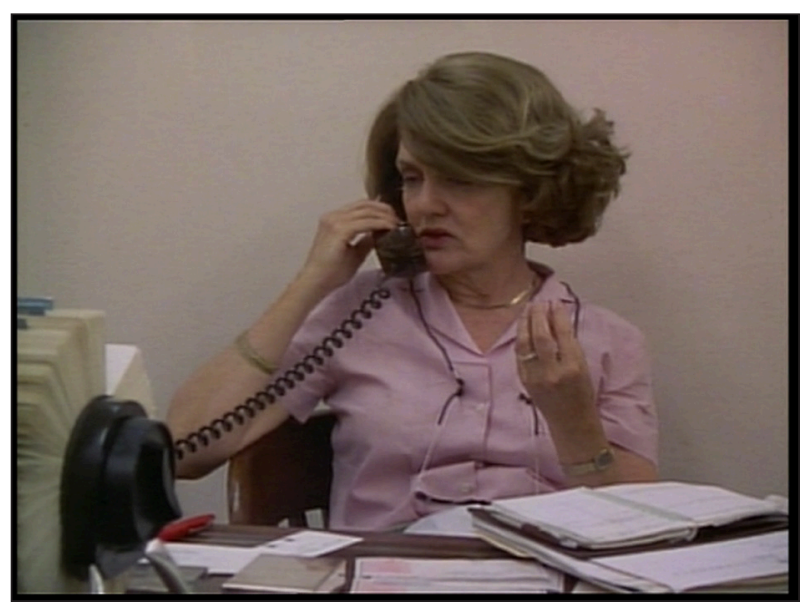

Figure 3 Elizabeth Barlow Rogers. the profile of light it emits. Rogers talks with conviction, and with heartfelt reference to 'future citizens of our parks', about the harsh glare and the aesthetic paucity of high-pressure sodium lighting, and the particularly harmful effect it has on the appearance of vegetation.

This insight into the non-visible work expended on taken-for-granted lighting provision is in itself of interest and value (and Rogers, speaking to one other party and namechecking other municipal bodies, is just one link in the chain), but is only part of what makes this sequence meaningful. I would suggest that it is the relative lack of identifiable aesthetic consideration at the point of Wiseman's production which throws into relief, and into significance, the care being directed by the film's subjects, outwards and elsewhere. Shot in a single set-up (plus a couple of cut-ins), facing Rogers more-or-less head on, her pale-pink shirt hardly defined against the off-white wall, the image static with the exception of some zoom re-framing, and illuminated only by what appears to be basic found lighting, the sequence is stylistically subdued to say the least. Articulating her vision for the lights, Rogers declares that 'God is in the details', but it is precisely this formal meticulousness that is absent from the film's own treatment of her conversation. In The Cinematic Footprint, Nadia Bozak writes about 'resource indulgence' in cinema (2011: 133), and how 'opulence of choice and an indulgence in materials' can be seen to have marked the history of film style, when that history is reviewed through the optics of energy supply and provision (122). Wiseman's muted aesthetic suggests a significant variation on that; the gap created between what is visible and what is being described becomes a kind of testament to infrastructural provision. Energy is not concentrated in what we see and hear or offered up for aesthetic consumption; it is elsewhere, for other people, for more people.

\section{THE EVERYDAY PARK}

Provision is the unobtrusive maintenance of availability. It is not a gift or a sacrifice, but more like the ongoing relationality Susan Leigh Star describes as characteristic of infrastructure (1999: 380). It thus follows that to register provision, to see it in play in the world or in a work of art, must be done in such a way that is informed by, and sensitive to, the scale of the everyday. For Michael Renov, this scale is invoked by all documentary film: 'the referent of the nonfiction sign', he writes, 'is meant to be a piece of the world [that] was once available to experience in the everyday' (1993: 31). Central Park is more determined than most films to retain a sense of that availability, and succeeds in doing so by bringing into contact with one another those contrasting categories of experience which Henri Lefebvre writes of as being constitutive of the everyday: 'everyday life and festival - 
mass moments and exceptional moments - triviality and splendour - seriousness and play - reality and dreams' (2014: 271). While many interesting films about people and their social world could be said to play these binary concepts off one another in some shape or form, Central Park is fundamentally shaped by (and is about) their coexistence.

This is in part because its very subject, the park, oscillates between normality and festivity, seriousness and play; after all, Central Park hosts commutes and lunch breaks as well spectacular shows, sessions of political and educational instruction as well as sunbathing and baseball. But it is not inevitable that a film would make room for all these aspects, and certainly not in the way that Central Park does - namely by distributing significance across its field, and by muting to the point of silence or invisibility any stylistic bracketing of particular sequences, moments or images. (Like many other writers on Wiseman, I am here indebted to Bill Nichols's notion of the 'mosaic' structure of his films [1981: 211].) It is a risk to conflate invisibility with neutrality, and I certainly do not claim that Central Park magically absolves itself from the mechanics of perspective, authority and partiality, so deeply embedded as they are in documentary practice. But it would be similarly unwise to ignore the considerable time bestowed by the film on a genuinely diverse range of activities, and to overlook how the lack of an evident hierarchical relationship between them might signal a striving for everydayness on the part of the film. ${ }^{12}$ Central Park includes within it a number of striking pro-filmic events, but the film asserts their continuity with other activities more than it does their inherent or integral significance.

This seems particularly deliberate in the film's treatment of performance. The 'shows' in Central Park are not climactic, and do not exert much if any gravitational pull on the film's subjects and their attention. Even when a large audience watches on, impressed and entertained, as is the case when Luciano Pavarotti and Kathleen

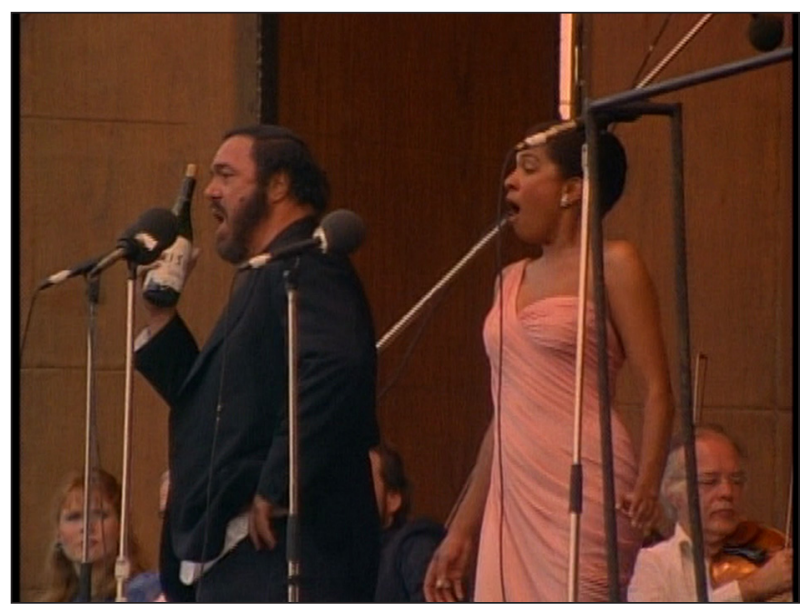

Figure 4 The opera singers.
Battle perform Donizetti's Elisir d'Amore as part of the 'Met in the Parks' series, the film deliberately subdues the sense of performers having an audience (Figure 4). We do see a large crowd, but only prior to seeing the singers on stage, and there is no attempt by Wiseman to generate through editing or shot composition a responsive or communicative dynamic between performers and audience. An elderly man and woman watch on from hospital beds, their facial expressions indiscernible. A female police officer stands, stoney faced, her back to the stage (Figure 5). Pavarotti and Battle receive their applause, but with no obvious acknowledgement of their audience. The contract between the entertainers and the entertained, at least as it is articulated by the film, is not characterized by rapt attention, or by that audience's privileged access to a moment of creative intensity achieved by exceptional and engrossing artists; in fact, Wiseman's treatment of the opera performance has much in common with the lawn-tractor exchange at the film's opening, where the question of mutual address was seen to be rather open and undetermined.

It is through the notion of 'address' that Wiseman's deployment of everydayness in Central Park can be more fully understood, particularly in those scenes which document acts of performance from a somewhat oblique perspective. In the opening pages of her recent study, Arts of Address, Monique Roelofs describes address as a 'force of quotidian agency and receptivity', and something that exists simultaneously through structures, modes, norms, scenes and scripts (2020: 2). Modes of address, Roelofs proposes, 'are forms of signification that we direct at people, nonhuman creatures, things, and places, and that these entities direct at us and eachother', with considerable capacity for both inclusion and exclusion (26). Particularly clear examples of 'address in action' can be found in those events (speeches, briefings, performances, tutorials, etc.) in which pre-nominated individuals take up a position of centrality, authority and agency before an

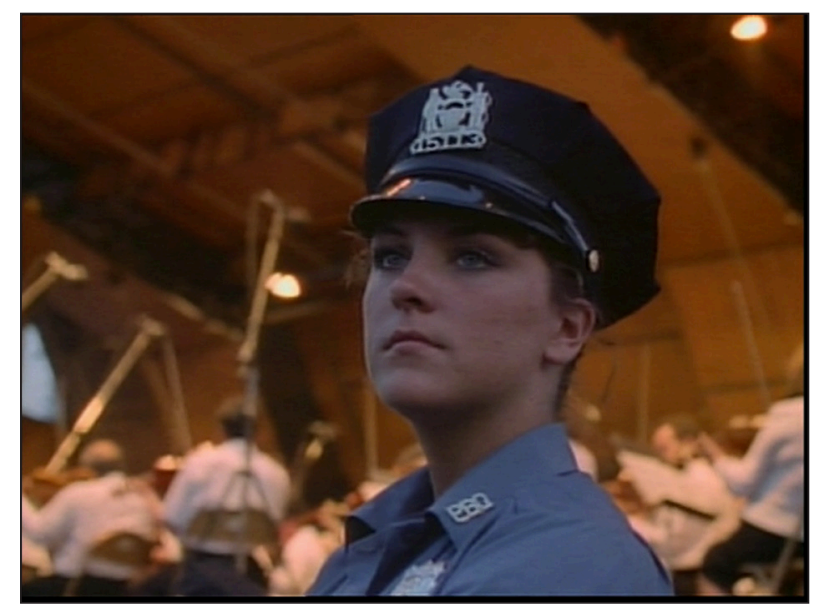

Figure 5 Present but not captivated. 
audience; at such times, the expectations of address (who is supposed to be listening, what constitutes an appropriate tone, who should be looking where) tend to be firmly in place. Such events permeate Central Park, and Wiseman's films more generally, but they are denied the shape and self-sufficiency which normally characterizes them. While it may be argued that, by capturing something in one context and then showing it another, all documentary films to some extent repurpose and redirect address, Central Park does so with the very particular effect of undoing the exclusivity and focus of performative address. If, as Roelofs suggests, 'address tends to separate addressees from nonaddressees', Central Park generates the impression that its shows are for everybody, or nobody in particular (9).

In one of the film's more amusing passages, Wiseman documents 'dinosaur day' at the park (Figure 6). Henry Stern, the Parks Commissioner who was previously seen in the Conservancy's board meeting, stands on a small stage wearing shorts and a sports jersey, talking about the enduring appeal of dinosaurs (with a tone and demeanor that give the distinct impression he's extemporizing). Behind a small barrier, a makeshift audience has formed, but with what prior knowledge or expectations it is very difficult to guess. The show culminates with the release of balloons, and a rather perfunctory 'that's it' from Stern. The camera picks out a series of individuals who we assume to be in the vicinity, but it is not clear whether they have been part of the small crowd, or are simply oblivious (they are not especially amused). A photographer points and focuses his lens, but seemingly in the opposite direction to the stage. Shortly after, we hear then see that some willing volunteers have been gathered to join a game, in which they imagine or invent new dinosaurs and their accompanying roars and rasps. Standing in a line, they each take a turn being handed a microphone, introducing and 'voicing' their creation, happy to participate but a little self-conscious. Across the whole passage, there is a studied ambivalence on the question

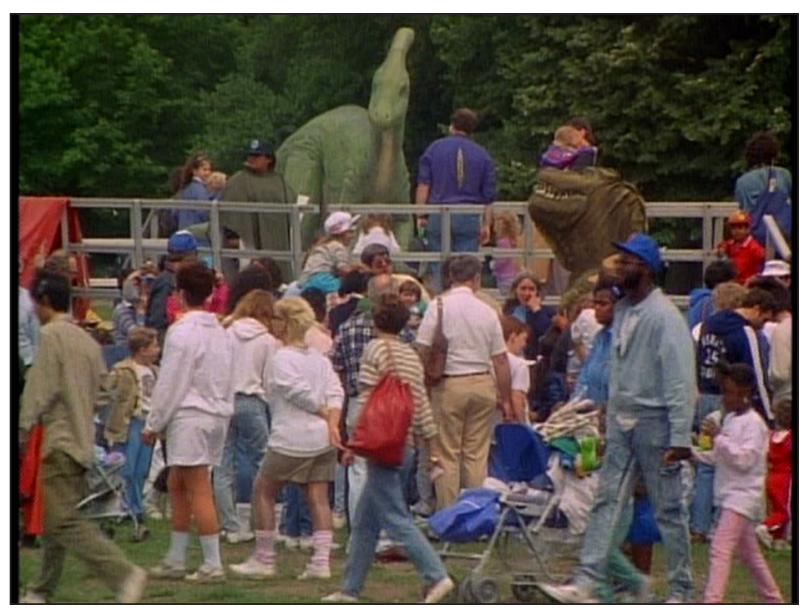

Figure 6 Dinosaur day. of address; to return to Roelofs's terms, 'relationality and directionality' are frayed at best (2020: 147). Henry Stern seems to be shaping his address to suit a young audience, but the film provides little evidence that they are its recipients. The dinosaur game is 'performed' on stage but appears to have almost as many participants as it does viewers. Are these, then, documents of failure and misjudgment?

I suggest not. Rather than gather evidence of (and rhetorically evaluate) performances which fail or succeed to entertain, or mimetically express an audience's experience of enthrallment or impatience, Central Park is instead registering the fact of these acts as part of the park's provision. These shows - Pavarotti and Battle, dinosaur day, Midnight Oil performing 'Beds Are Burning', a group demonstrating a West African Lamba dance, Mayor Ed Koch addressing a Catholic assembly, a black man performing Hendrix-like guitar solo at the Mississippi picnic - are woven into the film's broader patchwork of everyday experiences, and its record of what Central Park's public have unexceptional access to. Their formal arrangement in the film is not supported by familiar markers (point of view, reaction shots, etc.), but instead bear the traces of what Caroline Levine call 'the strange patterns of institutional time' (2015: 57). ${ }^{13}$ This is what it looks and sounds like when a film's expressive form normalizes - one might even say institutionalizes - the provision of performance.

\section{CONCLUSION: THE LIMITS OF PROVISION}

In Living a Feminist Life, Sara Ahmed finds great significance in the way that Virginia Woolf positions Mrs. Dalloway in relation to gatherings of people, and how such gatherings (and their directions of movement) are normalized. Caught up in one-way human traffic, Mrs. Dalloway 'catches sight of her own disappearance', realizing that her life's trajectory has been set, and set by the restrictive parameters of bourgeois womanhood (2017: 44). Ahmed is concerned with how the 'machinery of man-made geography' can be an instrument of compulsion, and a serious challenge to individual subjectivities; 'once a crowd is directed', she writes, 'a crowd becomes directive' (45). Any appraisal of Central Park as a film which documents social provision must reckon with the fact that it does very little to interrogate the antisocial potential of the park's organization, certainly at the level of individual experience. This returns us to a question raised earlier, concerning the film's rhetorical positioning of the park. In short, is Central Park considered by Wiseman's film (and its subjects) to be indicative of, or exceptional to, conventional and coercive political structures? Is Central Park a document of somewhere Mrs. Dalloway would be obliged to rehearse her 'steady and solemn progress', or would she instead be granted access to new and unregulated 
perspectives on herself and her world (Ahmed 46)? In the terms offered by Harney and Moten, does Wiseman's film ultimately endorse 'resistance from above' (2013: 76) in the form of normative and monitored arrangements, or 'the fugitive art of social life' (73)?

Central Park certainly feels like more of the former; it dedicates considerable attention to the implementation of assigned roles, often in organized gatherings, and includes no passages in which the film could be said to responsively adjust to the unforeseen actions of its subjects. Compare, for example, Symbiopsychotaxiplasm Take One (William Greaves, 1971), another film confined to the parameters of Central Park (albeit at a very different historical moment), but one animated by the surprising redirections the park provides. William Greaves's filmshoot within a film, in which Greaves himself plays a playful filmmaker leading a baffled but curious crew, has a game-like quality made possible by the park. (The rather bitter aspect of the film's premise is that a black filmmaker would need to experimentally perform - rather than 'just' undertake - the role of director.) Symbiopsychotaxiplasm delights in being thrown off course by apparently unpredictable arrivals, departures and turns in behaviour, and celebrates the anarchic and liberatory potential of park life; alongside it, Wiseman's film looks to be in thrall to procedural logic. ${ }^{14}$

But does the tendency toward regularity in Central Park really mark it as a conservative film, a film which resists the potential for human efforts towards more equal, just and freeing social configurations? I argue not, and that the key ideas explored in this essay - infrastructure, the commons, the everyday - help to elucidate how political possibility in Central Park is not figured as action in its familiar sense, but rather as what is in place. Yes, this entails a risk of accepting too readily the inevitably of a people's physical situation, but it also helps to expand the field of what we attend to when studying films of located human behaviour. Appreciating the 'provisionality' of the filmed world presents a number of methodological challenges, and it is true that few films will offer such an appropriate or convenient subject as the spatially discrete, exhaustively studied Central Park. But if we are to accept Erika Balsom's invitation to consider documentary films' participation in a 'reality-based community', the question of what is shown to have been provided and/or denied is one that deserves to be asked (2017).

\section{NOTES}

1 Although it is outside the purview of this essay, there is also the important component of an implied and anticipated public viewership of the documentary, and the attendant questions about Wiseman's working with and through PBS (Public Broadcasting Service). The filmmaker's own reflections on his 'service' to a public can be found in 'Privacy and Documentary Filmmaking', a short article published in Social Research (2001). I am grateful to Stefan Solomon for emphasizing to me the importance of this aspect of Wiseman's publicness - and for sharing a range of other insightful observations about the film.

2 A useful overview can be found Jeffrey Geiger, American Documentary Film: Projecting the Nation (2011).

3 The film's cinematographer was long-time Wiseman collaborator John Davey.

4 While this is a vast field which resists summary, some key texts relating to American cinema include: Miriam Hansen, Babel and Babylon: Spectatorship in American Silent Film (1994); Edward Dimendberg, Film Noir and the Spaces of Modernity (2004); David James, The Most Typical Avant-Garde: History and Geography of Minor Cinemas in Los Angeles (2005); Jacqueline Najuma Stewart, Migrating to the Movies: Cinema and Black Urban Modernity (2005).

5 The infamous attack on the 'Central Park jogger', which triggered the racist calamity depicted in When They See Us, took place on the cusp of this film's release. With hindsight, its total absence from Central Park has a disconcerting effect.

6 It is important to recognize that infrastructural projects are invariably bound up with publics way beyond those visible to its 'users'. Jane Hutton (2020) details the importance of Peruvian guano as a fertilizer for Central Park, and the imbrication of this reliance in networks of human and ecological exploitation.

7 The founding of the park necessitated the razing of Seneca Village, a predominantly black community, after the governmental seizing of land through 'eminent domain'. For an account of historical and archaeological research into the community and the park, see Diana Dizerega Wall et al. (2004).

8 The emphasis on structure and structural rhetoric is a significant feature of one of the few book-length studies of Wiseman's films: Benson and Anderson's Reality Fictions: The Films of Frederick Wiseman (1989).

9 For a detailed account of the film's leitmotifs, see Schwartz (1995).

10 For example, Guerin (2000); McQuire (2005); Jacobson (2010); Bozak (2011).

11 Jane Bennett (2010) takes up the major North American blackout in 2003 as a case study for her theorization of human/ non-human assemblages.

12 A rough, indicative list of social activity in Central Park would include: sunbathing, teaching, marrying, cycling, performing, competing, lecturing, running, arguing, cleaning, rescuing, swimming, dining, fundraising, mourning, policing, birdwatching, tree-felling, advocacy and childcare.

13 The notion of the institution is of course a recurrent and significant one in the discourse surrounding Wiseman's films. Carol Levine's interpretive analyses in Forms (2015) offer an excellent model of how the phenomenon of the institution can be sensitively and imaginatively factored in to our readings of artworks.

14 Martha Shearer notes how Central Park as a setting is liable to resist expectations of, and associations with, realism (2016, 90-92)

\section{COMPETING INTERESTS}

The author has no competing interests to declare.

\section{AUTHOR AFFILIATION}

Adam O'Brien (D) orcid.org/0000-0002-9527-4076

Department of Film, Theatre \& Television, University of Reading, UK

\section{REFERENCES}

Ahmed, S. 2017. Living a Feminist Life. Durham and London: Duke University Press. DOI: https://doi. 
org/10.1215/9780822373377

An Architektur. 2010. On the Commons: A Public Interview with Massimo De Angelis and Stavros Stavrides. e-flux, 17, June. Available at https://www.e-flux.com/ journal/17/67351/on-the-commons-a-public-interviewwith-massimo-de-angelis-and-stavros-stavrides/.

Arendt, H. [1958] 2018. The Human Condition, 2nd ed. Chicago: University of Chicago Press.

Armstrong, D. 1989. Wiseman and the Politics of Looking: Manoeuvre in the Documentary Project. Quarterly Review of Film and Video, 11(4): 35-50. DOI: https://doi. org/10.1080/10509209009361325

Baldauf, A, et al. 2016. Introduction: Having to Make it, Without Being Able to.... In: Bladauf, A, et al. (eds.), Spaces of Commoning: Artistic Research and the Utopia of the Everyday. Berlin: Sternberg Press.

Balsom, E. 2017. The Reality-Based Community. e-flux, 83, June. Available at: https://www.e-flux.com/ journal/83/142332/the-reality-based-community/.

Bellamy, BR, LeMenager, $\mathbf{S}$ and Szeman, I. When Energy is the Focus: Methodology, Politics, and Pedagogy. Postmodern Culture, 26(2). DOI: https://doi.org/10.1353/ pmc.2016.0004

Bennett, J. 2010. Vibrant Matter: A Political Ecology of Things. Durham and London: Duke University Press: pp. 24-38. DOI: https://doi.org/10.1215/9780822391623

Benson, TW and Anderson, C. 1989. Reality Fictions: The Films of Frederick Wiseman. Carbondale and Edwardsville: Southern Illinois University Press.

Bozak, N. 2011. The Cinematic Footprint: Lights, Camera, Natural Resources. Rutgers University Press, 2011.

Brunsdon, C. 2012. The Attractions of the Cinematic City. Screen, 53(3): 209-227. DOI: https://doi.org/10.1093/ screen/hjs021

Diana Dizerega Wall, et al. 2004. The Seneca Village Project: Working With Modern Communities in Creating the Past. In: Shackel, PA and Erve, J (eds.), Places in Mind: Public Archaeology as Applied Anthropology. Abingdon; New York: Routledge.

Dimendberg, E. 2004. Film Noir and the Spaces of Modernity. Cambridge, Mass; London: Harvard University Press.

Elias, AJ. 2016. Art and the Commons. ASAP/Journal, 1(1): 3-15. DOI: https://doi.org/10.1353/asa.2016.0008

Forsey, J. The Promise, the Challenge, of Everyday Aesthetics. Aisthesis: Pratiche, linguaggi e saperi dell'estetico, 7(1): 5-21. DOI: https://doi.org/10.13128/Aisthesis-14608

Geiger, J. 2011. American Documentary Film: Projecting the Nation. Edinburgh University Press. DOI: https://doi. org/10.3366/edinburgh/9780748621477.001.0001

Grant, BK. 1992. Voyages of Discovery: The Cinema of Frederick Wiseman. Urbana and Chicago: University of Illinois Press.

Guerin, F. 2000. A Culture of Light: Cinema and Technology In 1920s Germany. Minneapolis: University of Minnesota Press.

Gupta, A. 2018. The Future in Ruins: Thoughts on the Temporality of Infrastructure. The Promise of
Infrastructure. In: Anand, A, Gupta, A and Appel, H (eds.), The Promise of Infrastructure. Durham, NC; London: Duke University Press, pp. 62-79. DOI: https://doi. org/10.1215/9781478002031-003

Hansen, M. 1994. Babel and Babylon: Spectatorship in American Silent Film. Cambridge, Mass; London: Harvard University Press.

Harney, S and Moten, F. 2013. The Undercommons: Fugitive Planning and Black Study. Wivenhoe: Minor Compositions.

Henley, P. 2020. Beyond Observation: A History of Authorship in Ethnographic Film. Manchester: Manchester University Press, 2020.

Hutton, J. 2020. Reciprocal Landscapes: Stories of Material Movements. Abingdon; New York: Routledge. DOI: https:// doi.org/10.4324/9781315737102

Jacobson, B. 2010. The 'Imponderable Fluidity' of Modernity: Georges Méliès and the Architectural Origins of Cinema. Early Popular Visual Culture, 8(2): 189-207. DOI: https://doi. org/10.1080/17460651003688089

James, D. 2005. The Most Typical Avant-Garde: History and Geography of Minor Cinemas in Los Angeles. Berkeley; London: University of California Press.

Kahana, J. 2008. Intelligence Work: The Politics of American Documentary. New York: Columbia University Press.

Lefebvre, H. 2014. The Critique of Everyday Life: The OneVolume Edition. London, New York: Verso Books.

Levin, 0. 2018. The Cinematic Time of the City Symphony Films: Time Management, Experiential Duration and Bodily Pulsation. Studies in Documentary Film, 12(3): 225-238. DOI: https://doi.org/10.1080/17503280.2018.1504370

Levine, C. 2015. Forms: Whole, Rhythm, Hierarchy, Network. Princeton: Princeton University Press. DOI: https://doi. org/10.1515/9781400852604

McQuire, S. 2005. Immaterial Architectures: Urban Space and Electric Light. Space and Culture, 8(2): 126-140. DOI: https://doi.org/10.1177/1206331204266372

Miyao, D. 2014. 'Bright Lights, Big City': Lighting, Technological Modernity, and Ozu Yasujirô's Sono yo no tsuma. positions: asia critique, 22(1): 161-201. DOI: https://doi. org/10.1215/10679847-2383885

Nichols, B. 1981. Ideology and the Image: Social Representation in the Cinema and Other Media. Bloomington: Indiana University Press.

Renov, M. 1993. 'Towards a Poetics of Documentary'. In: Renov, M (ed.), Theorizing Documentary (1993). Los Angeles: American Film Institute. pp. 12-36.

Rosenzweig, R and Blackmar, E. 1992. The Park and the People: A History of Central Park. Ithaca, N.Y.: Cornell University Press.

Saito, Y. 2017. Aesthetics of the Familiar: Everyday Life and World-Making. Oxford: Oxford University Press. DOI: https:// doi.org/10.1093/oso/9780199672103.001.0001

Schwartz, RA. 1995. Frederick Wiseman's Modernist Vision: Central Park. Literature/Film Quarterly, 23(3): 223-228.

Sennett, R. 2018. Building and Dwelling: Ethics for the City. London: Penguin Books.

Shearer, M. 2016. New York City and the Hollywood Musical: 
Dancing in the Streets. London: Palgrave Macmillan. DOI: https://doi.org/10.1057/978-1-137-56937-0

Star, SL. 1999. The Ethnography of Infrastructure. American Behavioral Scientist, 43(3): 377-391. DOI: https://doi. org/10.1177/00027649921955326

Stein, E. 2019. Neoliberal Cartographies: The Grid in Independent New York Film. New Review of Film and Television Studies, 17(3): 364-378. DOI: https://doi.org/10.1 080/17400309.2019.1622890

Stewart, JN. 2005. Migrating to the Movies: Cinema and Black Urban Modernity. Berkeley; London: University of California Press.

Warner, M. 2002. Publics and Counterpublics. Public Culture, 14(1): 49-90. DOI: https://doi.org/10.1215/08992363-14-1-49

Wiseman, F. 2001. 'Privacy and Documentary Filmmaking.' Social Research, 68(1): 41-47.

\section{FILMOGRAPHY}

Annie Hall. 1977. [Film] Woody Allen. USA. Rollins-Joffe Productions.

Canal Zone. 1977. [Film] Frederick Wiseman. Zipporah Films. Ex Libris. 2017. [Film] Frederick Wiseman. Zipporah Films. High School. 1968. [Film] Frederick Wiseman. Zipporah Films. Hospital. 1970. [Film] Frederick Wiseman. Zipporah Films.

Public Housing. 1997. [Film] Frederick Wiseman. Zipporah Films.

Sono yo no tsuma/That Night's Wife. 1930. [Film] Yasujirô Ozu. Shochiku.

Symbiopsychotaxiplasm Take One. 1968. [Film] William Greaves. Take One Productions.

When They See Us. 2019. [Television Mini Series]. Ava DuVernay. ARRAY Filmworks.

TO CITE THIS ARTICLE:

O'Brien, A. 2021. Central Park and its Provision. Open Screens, 4(1): 9, pp. 1-13. DOI: https://doi.org/10.16995/os.47

Submitted: 28 August 2020 Accepted: 28 April 2021 Published: 07 June 2021

COPYRIGHT:

(c) 2021 The Author(s). This is an open-access article distributed under the terms of the Creative Commons Attribution 4.0 International License (CC-BY 4.0), which permits unrestricted use, distribution, and reproduction in any medium, provided the original

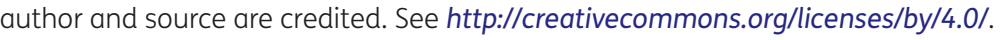

Open Screens is a peer-reviewed open access journal published by Open Library of Humanities. 